\title{
Precariedad laboral en el turismo español bajo la perspectiva de género
}

\author{
Gema Martínez-Gayo* Violante Martínez Quintana** \\ Universidad Nacional de Educación a Distancia (España)
}

\begin{abstract}
Resumen: El buen momento del sector turístico español no ha evitado que se caracterice por su temporalidad, horarios complejos o una elevada rotación del personal. Las trabajadoras siguen soportando precariedad laboral, puestos de trabajo tradicionales de género y pocas posibilidades de ascenso profesional. Por tanto, este artículo pretende averiguar en qué medida continúa la desigualdad de género en las condiciones de trabajo de la fuerza laboral turística española entre los años 2008 y 2017 atendiendo al tipo de jornada, la segregación laboral o los salarios percibidos. Para ello se realizó un análisis de los principales datos secundarios en ese mismo período y una revisión de la literatura especializada sobre la situación del mercado de trabajo turístico español bajo la perspectiva de género. Se concluyó, entre otros, que las diferencias de género en el sector turístico persisten, ya que las trabajadoras continúan percibiendo salarios inferiores a los de sus compañeros y concentrando más del 70\% de los contratos a tiempo parcial en cualquier momento de estos diez años.
\end{abstract}

Palabras Clave: Turismo; Género; Precariedad laboral; Empleo temporal; Salarios inferiores y crisis económica.

\section{Labour precariousness in Spanish tourism from a gender perspective}

Abstract: The good moment of the Spanish tourist sector has not prevented it from being characterised by its temporality, complex working hours or a high turnover of staff. Female workers continue to endure job insecurity, traditional gender jobs and few possibilities for professional advancement. Therefore, this article aims to find out to what extent gender inequality continues in the working conditions of the Spanish tourist workforce, between the years 2008 and 2017 according to the type of working day, the labour segregation or the salaries received. To this end, an analysis of the main secondary data in the same period and a review of the specialized literature about the Spanish tourist labour market from a gender perspective were carried out. It was concluded, among others, that gender inequalities in the tourism sector persist as women workers continue to receive lower salary than their peers and concentrating more than $70 \%$ of part time contracts at any time during these ten years.

Keywords: Tourism; Gender; Labour precariousness; Temporary job; Lower salaries; Economic crisis.

\section{Introducción}

Los viajes y el turismo son importantes impulsores de la economía mundial, a la par que grandes generadores de empleo que alcanzan los 119 millones a nivel mundial (World Travel \& Tourism Council, 2018), todo ello a pesar de la situación económica y financiera que se ha vivido en los últimos diez años.

Señales de este buen momento son las llegadas de turistas internacionales por todo el mundo, que se incrementaron en los primeros ocho meses de 2017 en un 7\% respecto al mismo período del año anterior. Este dato supone el octavo año de crecimiento consecutivo, y viene a confirmar las predicciones optimistas sobre el futuro del sector (OMT-UNWTO, 2017a). En cuanto al empleo generado, el sector turístico es responsable de uno de cada once empleos a nivel mundial conseguidos en el año 2016, tal y como refleja la publicación del Panorama OMT del turismo internacional (OMT-UNWTO, 2017b).

\footnotetext{
Doctoranda de la Universidad Nacional de Educación a Distancia (España); E-mail: gmartinez9@alumno.uned.es; https://orcid. org/0000-0003-1024-6429

** Universidad Nacional de Educación a Distancia (España); E-mail: vmartin@poli.uned.es; https://orcid.org/0000-00016208-1318
} 
Este panorama del turismo internacional tiene continuidad en lo mostrado por el estado del sector turístico español, el cual cerró el tercer trimestre de 2017 con un nuevo aumento interanual del PIB turístico y una mejora de resultados de las empresas centradas en esta actividad (Exceltur, 2017:3). En ese mismo año también se incrementó el empleo de las empresas del sector en casi un 5\%, por encima del resto de los sectores de nuestra economía en prácticamente un punto (Exceltur, 2017:4). Estos datos vienen respaldados tanto por los buenos resultados de la ocupación hotelera en los diez primeros meses del 2017, donde las pernoctaciones se incrementaron prácticamente un $3 \%$ respecto al mismo espacio temporal del año anterior, como por la facturación media diaria por habitación ocupada y los ingresos medios por habitación disponible que también aumentaron en ese mismo período temporal (INE, 2017).

A pesar de estas cifras tan positivas, lo cierto es que no parece haberse plasmado en una mejora de las condiciones laborales de las personas empleadas en el sector turístico español. Éstas han tenido que hacer frente a una coyuntura económica desfavorable, un contexto de cambios legislativos relativos a la contratación, despidos y aplicación de convenios colectivos (Canalis, 2015), y la persistencia de los problemas estructurales del sector, como la orientación hacia un turista de "sol y playa". La fuerza laboral empleada en las actividades turísticas españolas continúa estando afectada por la discontinuidad temporal y por la elevada rotación del personal. El cambio frecuente de la fuerza laboral incide a su vez en la baja motivación del empresariado del sector para invertir en formación, lo que sin duda acaba afectando a los bajos salarios que se perciben en muchas de las actividades turísticas (Pou, 2012). A ello debemos añadir que, aunque se han ido supliendo en gran medida los bajos niveles formativos que tradicionalmente caracterizaban a la fuerza laboral del sector, esta nueva fuerza de trabajo más formada y cualificada no llega a ocupar finalmente los puestos directivos del sector. Esto ha dado lugar a una sobrecualificación del personal, que junto con la elevada estacionalidad y los horarios irregulares hacen poco atractivos estos puestos, desincentivando la permanencia en los mismos (Marrero, 2014; Muñoz, 2016).

Las reformas legislativas que afectaron al empleo en un contexto de crisis económica se plasmaron básicamente en la entrada en vigor de Ley 3/2012 de 6 de julio de medidas urgentes para la reforma del mercado laboral. Entre los cambios más importantes, y que afectan al sector turístico, encontramos aquellos vinculados con el contrato a tiempo parcial el cual ha pasado de considerarse un instrumento para permitir la conciliación laboral y familiar a un concebirse como un método para favorecer la gestión flexible del empresariado. Esto ha permitido ampliar con horas complementarias y extraordinarias lo originalmente pactado, lo que anteriormente estaba prohibido (Miguélez, 2015; Secretaría de Acción Sindical de UGT, 2016). Además, se abarató y se facilitó el despido y se introdujeron cambios que favorecían la reducción de los salarios por parte del empresariado de manera unilateral (Secretaría de Acción Sindical de UGT, 2016). Estas medidas de ajuste salarial no han tenido el mismo efecto en todos los sectores de la economía española, siendo mucho más acusados en el sector servicios donde ya abundaban los bajos salarios antes de la introducción de esta reforma (Miguélez, 2015). Por ejemplo, en las actividades de la hostelería las remuneraciones están por debajo tanto de la media de la economía nacional como del sector servicios, siendo éste un rasgo permanente que se ha visto agudizado por la introducción de estas medidas (Porras, Hinojosa, Vargas, De la Rosa, y Canalis, 2015).

Con todo este marco laboral, parece oportuno detenerse de manera específica en la situación de las mujeres que trabajan en las actividades turísticas españolas. No sólo por los rasgos generales que caracterizan el empleo femenino, como por ejemplo la segregación ocupacional-dificultades de ascenso en la escala laboral o los menores salarios percibidos-, sino también por cómo se han visto ellas afectadas por la situación de crisis económica y las reformas legislativas mencionadas con anterioridad. Las trabajadoras del mercado laboral español habrían incrementado su población activa en los años iniciales de crisis económica, en parte como trabajadores adicionales para compensar la pérdida de ingresos en sus hogares. Este hecho se habría producido en nuestra economía hasta el año 2012, favorecido por el efecto desánimo que llevaban sufriendo los hombres en este período ante las malas condiciones laborales provocando un abandono del mercado laboral y, por tanto, una caída de las cifras de actividad. En los años 2013 y 2014 las trabajadoras comienzan a ver reducida su presencia debido no sólo al inicio, también para ellas, de ese proceso de desánimo por la extensión de la crisis económica, sino también por la propia tendencia estructural de nuestro mercado de trabajo que prima la contratación preferente de hombres ante los síntomas de recuperación de ciertas actividades (Ruesga, Martín, Pérez, y Viñas, 2014:226). Estas mayores pérdidas de empleo ocupado por mujeres coincidentes con las segundas fases de la crisis se pueden deber tanto a la extensión de dicha situación económica a toda la economía, como a las políticas implementadas desde el gobierno en estos períodos, los cuales no suelen tener en cuenta las diferencias de género. De este modo los recortes de gasto público en cuidados como la dependencia o 
los servicios sociales se ven suplidos en parte por un aumento del trabajo no remunerado de las mujeres, situación que se ha ido repitiendo a lo largo del tiempo (Ferguson, 2009).

La situación actual de emergencia sanitaria, provocada por el coronavirus COVID-19, genera una serie de problemáticas relacionadas con el empleo que previsiblemente contarán con una repercusión negativa en el ámbito que nos ocupa: el turismo. La todavía sensación de incertidumbre, dado el desconocimiento que aún se posee sobre el tiempo necesario para controlar la epidemia o las medidas que finalmente se tomarán para contrarrestar sus efectos, no nos permiten realizar un pronóstico fiable. Lo que sí parece previsible es que el turismo se va a ver afectado por las posibles cancelaciones y restricciones de movilidad y aforo (Iriondo, 2020). Este aspecto afecta de manera importante a España donde estas ramas de actividad concentran a una parte importante de su fuerza laboral. Dado que todavía estamos inmersos en esta situación no podemos contar con datos de la repercusión final de este virus en el trabajo turístico y cuáles son los colectivos más afectados. A este respecto, resulta necesario evaluar su estado anterior, la calidad de los empleos y las desigualdades existentes dentro de su mercado de trabajo para poder realizar en un futuro un análisis efectivo de sus consecuencias. Por tanto, el propósito de este artículo es conocer qué tipo de desigualdades de género existen, y la precariedad laboral que conlleva, en el mercado laboral turístico español. Para ello se realizará una investigación descriptiva y analítica, de las condiciones laborales en estas actividades en los últimos años. Principalmente se utilizarán los datos secundarios de Eurostat y el Instituto Nacional de Estadística, recogidos en el apartado cuatro, y del análisis de la bibliografía sobre dicha temática que aparece a continuación. El estudio realizado permite afirmar que dichas desigualdades entre mujeres y hombres que trabajan en dicho sector persisten todavía. Las trabajadoras siguen concentrando la mayor parte de los contratos a tiempo parcial del sector, los cuales proporcionan menores beneficios que aquellos con jornadas completas, y siguen percibiendo menores salarios que sus compañeros a lo largo de todo el periodo analizado.

\section{Marco teórico en el sector turístico bajo la perspectiva de género}

La literatura especializada en el sector turístico español comienza en las décadas de los ochenta y noventa del siglo XX. Los factores personales y laborales de la presencia mayoritaria de las mujeres en la hostelería y la restauración han sido en esta etapa inicial de estudio, el punto de mira más importante, y donde más estudios e investigaciones se han llevado a cabo hasta el momento presente. La precariedad laboral y las desigualdades son los pilares en los que se asienta este objeto de indagación que entronca, a su vez, con la dinámica de estudios en el proceso de incorporación de las mujeres al mercado laboral, con el retraso de los estudios universitarios de las enseñanzas del turismo (López Bonilla y López Bonilla, 2004), que supone una respuesta tardía del sistema educativo a la demanda real del mercado turístico español. Las evidencias halladas muestran la existencia de tres etapas distintas, una primera hace referencia a los enfoques iniciales de género en el turismo en el siglo XX, la segunda desarrolla enfoques novedosos en el contexto de crisis económica, y la tercera aporta una metodología de estudio concreta de corte feminista, que conforman los ejes principales del análisis de género en los trabajos del sector turístico.

\subsection{Enfoques iniciales de género en el turismo en el siglo $X X$}

Los enfoques iniciales de género en el turismo en el siglo XX parten de la diferenciación de los estereotipos, identidades y funciones sociales que se asignan a mujeres y hombres, en todos los órdenes de la vida en sociedad (personal, familiar, profesional, social, espiritual). A partir de ahí el núcleo principal se dirige al acceso y participación en la estructura ocupacional, que se caracteriza por una subrepresentación y una sobrerrepresentación en categorías ocupaciones según el sexo, así como el desigual acceso al tiempo libre, la motivación y las preferencias en los viajes. Otros enfoques se orientan en los comportamientos de turistas como consumidores de productos y servicios fuera de la legalidad, sin tener en cuenta los derechos de las personas y buscando su explotación sexual.

Persisten la teoría del Capital Humano y la teoría de la Segmentación, que siguen dominando en las interpretaciones y explicaciones del lugar que ocupan las mujeres en el mercado de trabajo, enfatizando la primera que las mujeres son menos productivas y volátiles y con menor salario, en tanto que la segunda contempla la existencia de un mercado dual que divide el mercado en primario (trabajos bien remunerados y posibilidades de ascenso) y en secundario (trabajos peor remunerados y sin posibilidades de ascenso). En ambas teorías las mujeres se hallan fuera de las oportunidades de mejora con respecto a los hombres, y es la maternidad y la conciliación familiar el bastión más difícil de paliar. El análisis 
de género irá desplazando estas teorías y construirá una teoría específica centrada en la realidad de las mujeres, basada en los principios de igualdad de oportunidades, para corregir las desigualdades y la precariedad a la que están mayoritariamente confinadas las mujeres en el mundo laboral. Este enfoque inicial de género se estructura en cinco fases que Henderson (1994:122) estableció, y que posteriormente fueron reanudadas por Swain (1995:254), a saber:

1) Fase invisible, en la que no hay mujeres, pese al desarrollo del turismo.

2) Fase compensatoria, que se ilustra con la famosa frase de Swain: "añádanse mujeres y agítese".

3) Fase de las diferencias dicotómicas, es decir, de las diferencias sexuales.

4) Fase de la perspectiva feminista, centrada especialmente en las mujeres.

5) Fase de los marcos conscientes del género, que analiza las relaciones, los roles y los estereotipos, y que sitúan a las mujeres en una posición de subordinación frente a los varones.

Posteriormente, Risman (1998) abre un campo interesante con la teoría del Género como estructura social con tres niveles de análisis (el individual, el interaccional y el institucional) que determinará el género en la estructura social, y que permitirá identificar los elementos que producen discriminación en las mujeres procedentes de los roles de género asignados, la conciliación de la vida familiar y laboral, y todos aquellos que dificultan la igualdad de acceso y de oportunidades en el ámbito laboral. Este modelo ha sido desarrollado, con posterioridad, por Segovia-Pérez, Figueroa-Domecq, Fuentes-Moraleda y Muñoz Bazon (2018) para el ámbito concreto del turismo. Ambas aportaciones nos permitirán entender las razones por las cuales las mujeres en estas actividades ocupan determinados puestos de trabajo, las barreras que se levantan en el momento de la contratación o cómo la cultura empresarial y el tamaño de la empresa turística son factores clave para comprender las posibilidades que tiene una trabajadora en el momento de ascender y ostentar una posición de poder dentro de la misma.

En España la perspectiva de género en los estudios sobre turismo llega tardíamente, y se encuentran investigaciones sobre la prostitución ilegal, la pornografía infantil, y estudios que atienden a los conflictos de actividades de ocio, en general, y al ocio en el turismo, en particular. Estudios que tienen en cuenta la función social del ocio, el tiempo libre y las actividades recreativas según el sexo, y que comportan una concepción distanciada de aquel ocio originario de la sociedad griega (la skholé griega), que vivía un ocio contemplativo como un medio de saber no utilitario (Martínez, 2006: 81). Existe toda una apología sobre el ocio desarrollada como la del filósofo Josef Pieper (2017) que lo define como uno de los fundamentos de la cultura, que tiene su origen en la fiesta y es de carácter contrario al esfuerzo; o la de Sue (1992) que lo describe de tipo material (actividades recreativas), de tipo social (generalización de las diversiones) y de tipo institucional (la colectividad se encarga de determinadas diversiones).

Dumazedier (1968) en su obra Hacia una civilización del ocio, plantea la realidad ambigua que presentan las definiciones que se han dado sobre el ocio, y sus múltiples y contradictorias facetas, y se centra en las tres funciones básicas: descanso, diversión y desarrollo de la personalidad. Se trata de un ocio democratizador en sociedades que disponen de tiempo libre y de vacaciones pagadas, que según la WLRA (1994: 13-16) (World Leisure \& Recreation Association) en su Carta sobre Educación del Ocio se refiere a un área específica de la experiencia humana; un recurso para el desarrollo personal, social y económico; fomenta la buena salud y el bienestar; es un derecho humano básico como la educación, el trabajo y la salud; se facilita cuando se tienen garantizadas las condiciones básicas de la vida; aumenta la calidad de vida; alivia la insatisfacción, el estrés, el aburrimiento, la falta de actividad física, de creatividad y la alienación, y se dispone de múltiples actividades de ocio en las sociedades que han experimentado profundas transformaciones económicas y sociales. En definitiva, el ocio y el turismo como elementos dinamizadores de las sociedades humanas producen cambios e interacciones sociales (Martínez, 2006: 215), y en el trascurrir del tiempo se conforma un ocio en ciudades metropolitanas (Martínez, 2019: 460) de las que surgen prácticas de ocio negativas como la drogadicción y la violencia juvenil en las zonas de destino turísticas.

La Ley 6/1994, de 16 de marzo (actualmente derogada ${ }^{1}$ ), de ordenación del turismo trató en el Capítulo II el tema de las profesiones turísticas, y en el artículo 41 se introdujo por primera vez la perspectiva de género. En la Ley 13/2016 de 28 de julio, de Turismo con vigencia desde el 31 de agosto de $2016^{2}$, tiene en cuenta lo preceptuado en la Ley 4/2005 de 18 de febrero, de Igualdad de Mujeres y Hombres. El enfoque de género se inicia con estudios sobre las características de los empleados y las empleadas, las condiciones de trabajo y la comparación con el resto de sectores de la economía del país. Destaca el sector hostelero español por haber sido pionero en los análisis del empleo de bajos salarios, la discriminación salarial por razón de sexo y las características principales del empleo femenino en general. 
La década de los noventa aplica esta tipología de estudios que tienen como centro de interés la participación laboral de las mujeres. Sarasa (1998:19-20) investiga que el turismo influye positivamente en la creación de empleo para las mujeres en zonas del litoral -turismo de sol y playa-, pero en las zonas rurales la oferta de trabajo es más reducida. El empleo femenino se caracteriza por soportar la estacionalidad, la precariedad laboral, percibir salarios bajos y tener carencias formativas.

\subsection{Enfoques novedosos en el contexto de crisis económica en el siglo XXI}

En la literatura internacional de turismo y género en el siglo XXI se observa una distribución de estudios e investigaciones repartida en tres grandes áreas: 1. Área de consumidoras y consumidores (Martínez, 2011), 2. Área de productoras y productores y 3. Área de objetos e imágenes para la producción turística (Gibson, 2001), vinculadas a los análisis de género de Henderson y Swain de finales del siglo XX. Son enfoques novedosos que coinciden con la llegada de la crisis económica en 2008, en los que proliferarán las desigualdades y la precariedad laboral generalizadas, como consecuencia del impacto de la crisis.

$\mathrm{El}$ área de productoras y productores es la que más producción literaria ha desarrollado hasta el momento presente, especialmente los estudios relacionados con el acceso al empleo, la segregación laboral y la discriminación en el empleo. Swain $(1995,2005)$ señaló la escasa atención que se había prestado a las diferencias de género hasta la mitad de la década de los noventa, momento en el que ya se había alcanzado la madurez para que el turismo incorporase el análisis de género. A partir de aquí aparecen evidencias cotejadas y más visibilizadas de las condiciones particulares de las mujeres en el mercado laboral turístico, la precariedad laboral, menores remuneraciones y segregación ocupacional. Se analizan más en profundidad, las causas de las diferencias salariales (Sparrowe e Iverson, 1999); la segregación ocupacional vertical y horizontal, y la discriminación salarial (Ramos, Rey-Maqueda y Tugores, 2002). La dirección de las empresas y el estilo de liderazgo se pronuncia con máximo interés, y se destaca su reducida presencia en puestos directivos y en los consejos de administración. Alonso (2011: 72) sostiene que la existencia de barreras en la promoción profesional de las mujeres, dificultan el acceso a puestos donde se toman decisiones empresariales. Igualmente, en estudios llevados a cabo en México se concluye que la industria hotelera mexicana no difiere de la tendencia generalizada, con un perfil de dirección masculinizado, y un techo de cristal para las mujeres (Trujillo, 2011: 148).

En esta misma corriente Huete, Brotons y Sigüenza (2016:84) detectan en el sector hotelero español que el nivel de estudios superiores de las mujeres no se corresponde con las ocupaciones que tienen, ni ocupan puestos directivos en la misma proporción que los varones. El género condiciona el puesto a desempeñar en un contexto en el que existe una división vertical de la mano de obra y las mujeres están en desventaja frente a los hombres (salario y condiciones laborales). La división horizontal del trabajo recluta a las mujeres en determinados tipos de ocupación (peor remunerados). Ser trabajadora joven con proyectos de maternidad puede ser un obstáculo para este tipo de empleos (Sigüenza, Brotons, y Huete, 2013). En el otro polo destaca la precariedad laboral representada en las camareras de piso, que durante la crisis económica han sufrido la devaluación de su trabajo, la imposición del trabajo a tiempo parcial, eventual y la subcontratación, con más carga de trabajo, y aumento de riesgos para la salud física y psíquica. En el libro de Ernest Cañada (2015) titulado Las que limpian los hoteles. Historias ocultas de precariedad laboral, se evidencia gran parte de esta precariedad laboral, como lo ejemplifican algunos testimonios:

- Estamos hechas polvo, seguimos trabajando a fuerza de pastillas (p.45).

- No trabajamos a un ritmo normal, siempre vamos a contrarreloj (p.56).

- Tenemos que hacer 24 habitaciones cada día, y hasta 10 y 12 salidas (p.62).

- A mí me han robado la salud, y como a mí a todas mis compañeras (p.70).

- Siempre he estado de año en año trabajando, siempre eventual (p.87).

- Te hacen un contrato de un año y luego te echan a la calle, porque si no te tienen que hacer fija (p.93).

- Ha llegado un momento en que con estas condiciones ya no quiero trabajar, es que me va la vida en ello (p.150).

El empleo desempeñado por las trabajadoras en la hostelería sigue percibiéndose como una prolongación del trabajo doméstico ajustado a sus habilidades naturales, lo que refuerza los roles tradicionales de género que se observan en los puestos de trabajo turísticos de mujeres y hombres, siendo los de las mujeres los que están más vinculados con las labores domésticas -limpieza, cocina, atención en mesa, etcétera- (Muñoz, 2012:116). De nuevo aparece la segregación horizontal y la vertical ${ }^{3}$ al tener los empleos femeninos menos posibilidades de promoción y ascenso (Alonso, 2008; McKenzie, 
2007; Obadić y Marić, 2009; Íñiguez, Plumed, y Latorre, 2014; Torrego, 2002; Rico y Gómez, 2005; García-Ramón, Cànoves, Salamaña, Valdovinos, y Villarino, 1995; Millán, Castro, y Morales, 2012). Esta tendencia también se aprecia entre las trabajadoras de alojamientos rurales caracterizados por su ubicación en el ámbito familiar, en el que los hombres se dedican al mantenimiento o la atención al cliente y las mujeres realizan tareas vinculadas con la limpieza o la cocina (Muñoz, 2012; Sampedro y Camarero, 2007).

Uno de los rasgos característicos de las desigualdades de género es la oferta del trabajo a tiempo parcial destinada para las mujeres, al estar asociada a un mejor acople con las tareas del cuidado. En una muestra de mujeres entrevistadas en España se obtuvo que ellas vinculaban la jornada parcial con las condiciones ofrecidas en el mercado, y no por las posibilidades de compatibilización con la vida familiar (Torns y Recio, 2012). La crisis económica de 2008 y las políticas de austeridad impactaron de manera importante en nuestro entorno europeo más inmediato, especialmente en los países del sur de Europa, entre los que se encuentra España junto a Italia, Grecia y Portugal- (Alcañiz y Monteiro, 2016:40). La hipótesis principal sostiene que la crisis ha repercutido a las mujeres por su mayor continuidad en el rol tradicional de género en las tareas del cuidado de las personas a cargo (Purcell, 1996:17). De manera paralela estudios más recientes (Ons-Cappa, Garcia-Pozo y Sánchez-Ollero, 2017) han podido constatar que la diferencia salarial por razón de género es un hecho que se da en todas las actividades valoradas.

\subsection{Ejes principales en el análisis de género en los trabajos del sector turístico}

Moreno y Cañada (2018) estructuran los ejes principales del análisis de género y ponen el primer foco de atención en la conceptualización del trabajo turístico, y se diferencian tres tipos de empleo: a) empleo directo, b) empleo indirecto y c) empleo inducido (Santana, 1997:76). En 2017 la Organización Internacional del Trabajo catalogó el término turismo incluyendo en él las actividades relacionadas con los servicios de alojamiento, de alimentación y entretenimiento, de gestión de viajes y actividades, y de atracción turística. Dichas actividades requieren dos categorías, la del trabajo decente en condiciones de libertad, equidad, seguridad y dignidad (Ghai, 2003:125), donde los derechos son protegidos, con remuneración adecuada y protección social (OIT, 1999), y la del turismo responsable que minimiza los impactos a nivel medioambiental, social y cultural.

La importancia de las mujeres en el turismo lo muestra Baum (2013) en su primer informe oficial sobre la situación de las mujeres en la hostelería, catering y turismo, que comprobó que a nivel global el 55\% de la fuerza laboral estaba representada por mujeres, al igual que otro estudio realizado por The World Travel \& Tourism Council (WTTC, 2014), que cataloga el trabajo turístico como la tercera fuerza laboral. En las tres últimas décadas se ha utilizado el termino feminización para dar cuenta de la flexibilización en las condiciones irregulares que reducen a las mujeres a trabajadoras de segunda clase (Kanji y Menon, 2001:1), así como el incremento de las desigualdades de género y la precariedad al aunar en ellas mismas el rol productivo y reproductivo (Morini, 2007). Por tanto, la feminización del empleo en el turismo lleva al empobrecimiento en muchas áreas de su mercado laboral, y constituye una de las razones de precarización que se aleja de las sinergias para alcanzar la igualdad de género y el empoderamiento de las mujeres.

Como se dijo anteriormente, las mujeres en el turismo se ubican de manera mayoritaria en la hostelería y restauración en actividades consideradas como una extensión del trabajo doméstico (Ordóñez, 2001; Muñoz-Bullón, 2009; Baum, 2013). Estas situaciones se han ido analizando a lo largo del tiempo en la literatura especializada, y han confluido en una perspectiva analítica que requiere diferenciar 5 ámbitos de análisis: trabajo informal, trabajo precario, criterios de selección de la fuerza de trabajo, brecha salarial y acoso sexual en el trabajo (Moreno y Cañada, 2018).

El trabajo informal está vinculado a condiciones vulnerables, sin ingresos, prestaciones sociales adecuadas y cobertura de seguridad social. La mayoría de los estudios no contemplan estas trabajadoras familiares no remuneradas (Ordóñez, 2001), que trabajan en contextos de pobreza, sin poder desarrollar capacidades y tomar decisiones (Moreno, 2017). El trabajo precario responde a regulaciones laborales que llevan a situaciones vulnerables y malas condiciones de trabajo (Benach, Muntaner, Solar, Santana y Quinlan, 2010). El concepto de precariedad sirve para identificar los aspectos más negativos del trabajo asalariado y las condiciones socio-laborales que comportan (Carrasquer y Torns, 2007). Es una forma atípica de empleo, que disminuye las obligaciones contractuales de los empleadores con respecto a sus trabajadores y trabajadoras (Recio, 2007). Son, en suma, situaciones de trabajo de gran flexibilidad y debilitamiento del sindicalismo, que 
conduce a la incertidumbre, vulnerabilidad y dependencia de los trabajadores (Cano, 2004). Rubio (2010) clasifica cuatro dimensiones en la precariedad: la temporalidad (inseguridad de la relación laboral), la vulnerabilidad (degradación de las condiciones de trabajo), la insuficiencia salarial (niveles salariales insuficientes de cara a cubrir las necesidades primarias), y la desprotección laboral (reducción de prestaciones de protección social).

Los trabajos turísticos, y muy especialmente los ubicados en el subsector de la hostelería, suelen caracterizarse por su carga de trabajo estresante, las extensas jornadas de trabajo, los horarios de trabajo flexibles en fines de semana o períodos tradicionalmente vacacionales (Martínez-Gayo, 2019). Que los grupos más vulnerables de nuestro mercado de trabajo como son las personas jóvenes, inmigrantes y las mujeres suelan ocupar puestos ubicados en estas actividades no hacen sino aumentar el riesgo de sufrir precariedad laboral. Estos trabajos son vistos por las personas jóvenes habitualmente como un punto de entrada al mercado de trabajo, y en el caso de las personas inmigrantes un sector de paso intermedio o comodín en el caso de necesidad. En el caso concreto de las mujeres inmigrantes puede producirse en él cierto estancamiento fruto de la segregación ocupacional y las barreras hacia una mejora sociolaboral que sería común a lo experimentado por todo el colectivo femenino (Albarracín y Gabinete Federal de Estudios de la Federación de Comercio, Hostelería y Turismo de CCOO, 2006). Esto encajaría con lo antes mencionado de la perpetuación de roles tradicionales de género, dado que las mujeres se ubicarían en determinadas tareas dentro de la actividad hostelera con peores condiciones laborales que se acabarían convirtiendo en un gueto femenino, donde se pueden crear subgrupos que en las que se dan conjuntamente las tres características: mujer joven e inmigrante (Torns, 2013).

Los criterios de selección de la fuerza de trabajo dan cuenta del trabajo adecuado para las mujeres y los hombres, así como, de las habilidades y actitudes que se requieren en la obtención de un empleo en el turismo. Todo ello puede fomentar brechas de género (división sexual del trabajo, dificultades en la conciliación de la vida laboral y familiar, trabajos como extensión del trabajo doméstico) que deben evitarse. Finalmente, la brecha salarial y el acoso sexual en el trabajo, albergan factores estructurales en la fuerza de trabajo y en las condiciones de empleo, que hacen propicio la existencia de los mismos. En consecuencia, se apuesta por la sostenibilidad en el turismo que posibilite el trabajo decente y no transgreda las situaciones de discriminación y desigualdades existentes por cuestiones de género. En estas circunstancias se hace posible la incorporación de la perspectiva de género en las políticas empresariales, turísticas y de empleo, al igual que su aplicación en la acción sindical (Moreno y Cañada, 2018). Moreno (2017) señala en el horizonte de turismo y género a los Objetivos de Desarrollo Sostenible (ODS) que favorecerán de aquí al 2030 el análisis crítico, la igualdad de género y las recomendaciones para la educación y la sensibilización. De esta manera, el crecimiento económico será sostenible e inclusivo, el empleo será productivo y el trabajo decente predominará para todas las personas.

\section{Perspectiva metodológica}

Desde la perspectiva metodológica se lleva a cabo un análisis tanto de la literatura especializada sobre la situación laboral de las mujeres en general y del sector turístico español de manera específica, como de los datos secundarios referidos a ese mismo ámbito. Para ello, se estudia la precariedad laboral a través de la jornada laboral y de los salarios percibidos (Guadarrama, Hualde y López, 2012:218). Además, se da cuenta en el mismo del nivel institucional al que hacía referencia Risman (1998, 2004).

Para conocer la situación y evolución de la calidad de los empleos turísticos ocupados por mujeres en España se comenzará por estudiar el estado general del sector turístico español a través de las variables afiliación a la Seguridad Social, tasa de temporalidad y número de personas desempleadas. Todas ellas provenientes de los datos estadísticos publicados por Turespaña, que es el organismo público encargado del Marketing de España como destino de viajes en el mundo. Los datos que proporciona sobre la Afiliación a la Seguridad Social en las actividades turísticas provienen de la explotación del fichero de los regímenes de la Seguridad Social que gestiona la Tesorería General de la Seguridad Social. Por su parte los correspondientes a la tasa de temporalidad y personas desempleadas pertenecen a la Encuesta de Población Activa elaborada trimestralmente por el INE y que ofrece información de los activos, ocupados y parados en las actividades turísticas (Turespaña, 2018). 
En el caso concreto del análisis de la desigualdad de género en la industria turística española se analizará la evolución de las siguientes variables:

- Trabajadoras/es turísticos.

- Feminización de las actividades turísticas.

- Feminización de la contratación a tiempo parcial en la industria turística.

- Ganancia media anual por trabajador/a en el subsector de la Hostelería.

Las tres primeras variables referentes a la evolución de la fuerza laboral, la feminización del sector y de sus actividades y la contratación a tiempo parcial han sido extraídas de Eurostat y la referente a la remuneración de la Encuesta Anual de Estructura Salarial y del VI Monitor Adecco sobre salarios. La Encuesta Anual de Estructura Salarial facilita estimaciones de la ganancia bruta anual por trabajador por jornada, sexo, sección y ocupación a través de los datos del Fichero de la Afiliación a la Seguridad Social, la Agencia Tributaria, las Haciendas Forales y de la Encuesta Trimestral de Coste Laboral. Su ámbito poblacional es nacional, incorporando todos los trabajadores por cuenta ajena incluidos en la Seguridad Social, y los datos salariales proporcionados son brutos (INE, 2018a). Por su parte Adecco, grupo empresarial dedicado a los Recursos Humanos, lleva a cabo anualmente los Monitores de Salarios. Éstos están basados en la Encuesta Trimestral de Coste Laboral donde se analiza la remuneración española del último año y la evolución de la misma respecto a años anteriores teniendo en cuenta el salario ordinario bruto antes de deducciones, retenciones y excluidos los pagos no regulares (Adecco, 2018). Por último, Eurostat es la oficina de la Unión Europea que provee de información estadística permitiendo realizar comparaciones entre regiones y países (Eurostat, 2018a). La European Labour Force Survey analiza la situación de la fuerza laboral europea, de personas de quince o más años, a través de los datos de los países miembros (Eurostat, 2018b). Se ha realizado el análisis de los años comprendidos entre 2008 y 2017, con la excepción de la variable "Ganancia media anual" la cual comprende hasta 2016, último dato disponible en la Encuesta Anual de Estructura Salarial. La elección de dicho periodo permite estudiar la incidencia de la crisis económica en nuestro país y su efecto en el empleo turístico, así como los últimos años de cierta recuperación en nuestra economía.

\section{El empleo del sector turístico español bajo la perspectiva de género.}

Desde el inicio de la crisis económica y hasta el año 2013, el sector turístico español experimentó una disminución del número de personas que trabajan en sus actividades. A partir de ese momento, se inicia un aumento que se extiende hasta 2017, no obstante, el montante se queda todavía por debajo de lo registrado en los inicios de la crisis económica (Eurostat, 2018c). Estos datos del empleo turístico español se ven respaldados por el número de personas afiliadas a la Seguridad Social en alta laboral en estas secciones. Tras un descenso sufrido en el año 2009, registrándose el número mínimo de personas afiliadas en dichas actividades de todo el periodo, se produce un aumento continuado hasta 2017. Además, desde el año 2014 las variaciones interanuales son positivas y superan todas ellas el $3 \%$ respecto al año anterior, siendo especialmente destacables el aumento en los años 2016 y 2017 (Turespaña, 2018) (Tabla 1).

Tabla 1: Evolución de las personas afiliadas a la Seguridad Social en las actividades turísticas.

\begin{tabular}{|c|c|c|}
\hline & Total & Variación interanual \\
\hline 2008 & 1.959 .557 & $+1,2 \%$ \\
\hline 2009 & 1.917 .405 & $\mathbf{- 2 , 2 \%}$ \\
\hline 2010 & 1.932 .224 & $+0,8 \%$ \\
\hline 2012 & 1.948 .374 & $+0,8 \%$ \\
\hline 2013 & 1.934 .542 & $-0,7 \%$ \\
\hline 2014 & 1.936 .225 & $+0,1 \%$ \\
\hline 2015 & 2.001 .448 & $+3,4 \%$ \\
\hline 2016 & 2.093 .334 & $+4,6 \%$ \\
\hline 2017 & 2.193 .730 & $+\mathbf{4 , 8 \%}$ \\
\hline
\end{tabular}

Fuente: Elaboración propia según los datos de Turespaña, 2008-2017, según los datos del Ministerio de Empleo y Seguridad Social. 
En el año 2017, el último analizado de nuestro periodo de estudio, se produjo un incremento interanual respecto al año anterior del número de personas ocupadas ${ }^{4}$ en el sector turístico. Este incremento ha sido superior en el caso de los y las trabajadoras extranjeras que para las autóctonas. Así en ese año, el 2017, un diecinueve por ciento de las personas ocupadas en el sector turístico español eran de origen extranjero, superando así su peso en el sector servicios y en el total de la economía española en ocho puntos porcentuales en ambos casos. El contexto económico también ha influido en el aumento del número de personas desempleadas del sector turístico. Éstas no cesaron de crecer entre el año 2008 y el 2013, momento que alcanza la cifra máxima del período superando las 460.000 personas, experimentando un descenso en los siguientes cuatro años. No obstante, la cifra de desempleados en el turismo en 2017 continuó siendo superior a la registrada en 2008 (Turespaña, 2018).

Otro dato que nos permite esbozar las condiciones laborales es la tasa de temporalidad ${ }^{5}$, dado que es una de las principales características del empleo del sector. Esta tasa en el sector turístico se ha incrementado de manera importante desde 2011 hasta el 2017, donde se supera el 35\%. Aunque existen dos pequeñas disminuciones en 2012 y 2015, lo cierto es que desde 2008 hemos asistido a un incremento de casi tres puntos en la tasa de temporalidad del sector, la cual se muestra superior a la del Sector Servicios en general en este período temporal (Turespaña, 2018). En este contexto laboral el número de trabajadoras turísticas en España descendió entre 2008 y 2013, para incrementarse desde 2014. No obstante, es preciso matizar, gracias a los datos de Eurostat (2018c), que su peso en el sector alcanzó su cota máxima entre 2012 y 2014, momento en el que suponían el $46 \%$ de la fuerza laboral turística. Desciende un punto un año después, porcentaje en el que se estabiliza hasta el año 2017 (Tabla 2).

\section{Tabla 2: Evolución absoluta (miles de personas) y relativa de las trabajadoras turísticas en España.}

\begin{tabular}{|c|c|c|c|c|c|}
\hline & & Total & Transporte aéreo & Alojam. y comidas & Agencias viajes \\
\hline \multirow{3}{*}{2008} & Total & 20469,7 & 53,3 & 1457,8 & 64,8 \\
\hline & Mujeres & $\begin{array}{c}8664,5 \\
\mathbf{4 2} \%\end{array}$ & $\begin{array}{l}21,8 \\
\mathbf{4 1} \%\end{array}$ & $\begin{array}{l}814,9 \\
\mathbf{5 6} \%\end{array}$ & $\begin{array}{l}47,2 \\
\mathbf{7 3 \%}\end{array}$ \\
\hline & Hombres & $\begin{array}{c}11805,2 \\
\mathbf{5 8 \%}\end{array}$ & $\begin{array}{l}31,4 \\
\mathbf{5 9 \%} \\
\end{array}$ & $\begin{array}{c}642,9 \\
\mathbf{4 4 \%} \\
\end{array}$ & $\begin{array}{l}17,6 \\
\mathbf{2 7 \%} \\
\end{array}$ \\
\hline \multirow{3}{*}{2009} & Total & 19106,9 & 50,8 & 1423,2 & 57,1 \\
\hline & Mujeres & $\begin{array}{c}8.373,8 \\
\mathbf{4 4 \%}\end{array}$ & $\begin{array}{l}23,6 \\
\mathbf{4 6} \% \\
\end{array}$ & $\begin{array}{c}786,4 \\
\mathbf{5 5 \%} \\
\end{array}$ & $\begin{array}{l}38,5 \\
67 \% \\
\end{array}$ \\
\hline & Hombres & $\begin{array}{c}10733,1 \\
\mathbf{5 6 \%} \\
\end{array}$ & $\begin{array}{l}27,3 \\
\mathbf{5 4 \%} \\
\end{array}$ & $\begin{array}{c}636,8 \\
\mathbf{4 5 \%} \\
\end{array}$ & $\begin{array}{l}18,6 \\
\mathbf{3 3} \% \\
\end{array}$ \\
\hline \multirow{3}{*}{2010} & Total & 18724,5 & 54,1 & 1383,2 & 55,7 \\
\hline & Mujeres & $\begin{array}{c}8300,8 \\
\mathbf{4 4 \%} \\
\end{array}$ & $\begin{array}{l}24,0 \\
\mathbf{4 4 \%} \\
\end{array}$ & $\begin{array}{l}748,5 \\
\mathbf{5 4 \%} \\
\end{array}$ & $\begin{array}{l}38,3 \\
\mathbf{6 9} \% \\
\end{array}$ \\
\hline & Hombres & $\begin{array}{c}10423,7 \\
\mathbf{5 6 \%} \\
\end{array}$ & $\begin{array}{l}30,0 \\
\mathbf{5 5 \%} \\
\end{array}$ & $\begin{array}{c}634,7 \\
\mathbf{4 6 \%} \\
\end{array}$ & $\begin{array}{l}17,4 \\
\mathbf{3 1 \%} \\
\end{array}$ \\
\hline \multirow{3}{*}{2011} & Total & 18421,4 & 49,6 & 1401,0 & 53,7 \\
\hline & Mujeres & $\begin{array}{c}8268,9 \\
\mathbf{4 5 \%} \\
\end{array}$ & $\begin{array}{l}20,4 \\
\mathbf{4 1 \%} \\
\end{array}$ & $\begin{array}{l}758,0 \\
\mathbf{5 4} \% \\
\end{array}$ & $\begin{array}{l}43,6 \\
81 \% \\
\end{array}$ \\
\hline & Hombres & $\begin{array}{c}10152,5 \\
\mathbf{5 5 \%}\end{array}$ & $\begin{array}{l}29,3 \\
\mathbf{5 9 \%} \\
\end{array}$ & $\begin{array}{c}643,0 \\
\mathbf{4 6} \% \\
\end{array}$ & $\begin{array}{l}10,1 \\
\mathbf{1 9 \%} \\
\end{array}$ \\
\hline \multirow{3}{*}{2012} & Total & 17632,7 & 38,9 & 1336,9 & 54,4 \\
\hline & Mujeres & $\begin{array}{c}8024,5 \\
\mathbf{4 6 \%} \\
\end{array}$ & $\begin{array}{l}16,7 \\
\mathbf{4 3} \% \\
\end{array}$ & $\begin{array}{l}700,8 \\
\mathbf{5 2} \% \\
\end{array}$ & $\begin{array}{l}42,8 \\
\mathbf{7 9} \% \\
\end{array}$ \\
\hline & Hombres & $\begin{array}{c}9608,2 \\
\mathbf{5 4 \%} \\
\end{array}$ & $\begin{array}{l}22,2 \\
\mathbf{5 7 \%} \\
\end{array}$ & $\begin{array}{c}636,2 \\
\mathbf{4 8 \%} \\
\end{array}$ & $\begin{array}{l}11,6 \\
\mathbf{2 1 \%} \\
\end{array}$ \\
\hline \multirow{3}{*}{2013} & Total & 17139,0 & 44,2 & 1332,6 & 55,7 \\
\hline & Mujeres & $\begin{array}{c}7823,2 \\
\mathbf{4 6} \% \\
\end{array}$ & $\begin{array}{l}15,8 \\
\mathbf{3 6 \%} \\
\end{array}$ & $\begin{array}{l}700,0 \\
53 \% \\
\end{array}$ & $\begin{array}{l}39,3 \\
71 \% \\
\end{array}$ \\
\hline & Hombres & $\begin{array}{c}9315,8 \\
\mathbf{5 4 \%}\end{array}$ & $\begin{array}{l}28,4 \\
\mathbf{6 4 \%} \\
\end{array}$ & $\begin{array}{c}632,6 \\
\mathbf{4 7} \% \\
\end{array}$ & $\begin{array}{l}16,4 \\
\mathbf{2 9} \%\end{array}$ \\
\hline
\end{tabular}




\begin{tabular}{|c|c|c|c|c|c|}
\hline \multirow{3}{*}{2014} & Total & 17344,2 & 44,2 & 1403,8 & 62,1 \\
\hline & Mujeres & $\begin{array}{c}7901,5 \\
\mathbf{4 6} \%\end{array}$ & $\begin{array}{l}18,4 \\
\mathbf{4 2} \%\end{array}$ & $\begin{array}{c}719,4 \\
\mathbf{5 1} \%\end{array}$ & $\begin{array}{l}35,5 \\
\mathbf{5 7 \%}\end{array}$ \\
\hline & Hombres & $\begin{array}{c}9442,7 \\
\mathbf{5 4} \% \\
\end{array}$ & $\begin{array}{l}25,8 \\
\mathbf{5 8 \%} \\
\end{array}$ & $\begin{array}{c}684,3 \\
\mathbf{4 9} \% \\
\end{array}$ & $\begin{array}{l}26,7 \\
\mathbf{4 3 \%}\end{array}$ \\
\hline \multirow{3}{*}{2015} & Total & 17866,1 & 41,1 & 1505,2 & 74,7 \\
\hline & Mujeres & $\begin{array}{c}8105,7 \\
\mathbf{4 5 \%} \\
\end{array}$ & $\begin{array}{l}17,8 \\
\mathbf{4 3} \% \\
\end{array}$ & $\begin{array}{l}769,1 \\
\mathbf{5 1 \%} \\
\end{array}$ & $\begin{array}{l}44,9 \\
60 \% \\
\end{array}$ \\
\hline & Hombres & $\begin{array}{c}9760,4 \\
\mathbf{5 5} \% \\
\end{array}$ & $\begin{array}{l}23,3 \\
\mathbf{5 7 \%}\end{array}$ & $\begin{array}{c}736,1 \\
\mathbf{4 9} \%\end{array}$ & $\begin{array}{l}29,8 \\
\mathbf{4 0} \%\end{array}$ \\
\hline \multirow{3}{*}{2016} & Total & 18341,55 & 38,0 & 1604,1 & 65,1 \\
\hline & Mujeres & $\begin{array}{c}8340,8 \\
\mathbf{4 5} \%\end{array}$ & $\begin{array}{l}15,5 \\
\mathbf{4 1 \%}\end{array}$ & $\begin{array}{c}839,5 \\
\mathbf{5 2} \%\end{array}$ & $\begin{array}{l}42,0 \\
\mathbf{6 4 \%}\end{array}$ \\
\hline & Hombres & $\begin{array}{c}10000,8 \\
\mathbf{5 5 \%}\end{array}$ & $\begin{array}{l}22,5 \\
\mathbf{5 9 \%}\end{array}$ & $\begin{array}{c}764,7 \\
48 \%\end{array}$ & $\begin{array}{l}23,1 \\
\mathbf{3 5 \%}\end{array}$ \\
\hline \multirow{3}{*}{2017} & Total & 18824,8 & 42,0 & 1637,1 & 65,5 \\
\hline & Mujeres & $\begin{array}{c}8558,5 \\
\mathbf{4 5 \%}\end{array}$ & $\begin{array}{l}16,4 \\
\mathbf{3 9 \%} \\
\end{array}$ & $\begin{array}{c}875,1 \\
\mathbf{5 3} \%\end{array}$ & $\begin{array}{l}42,4 \\
\mathbf{6 5 \%}\end{array}$ \\
\hline & Hombres & $\begin{array}{c}10266,3 \\
\mathbf{5 5 \%}\end{array}$ & $\begin{array}{l}25,7 \\
\mathbf{6 1 \%} \\
\end{array}$ & $\begin{array}{c}762,0 \\
\mathbf{4 7 \%}\end{array}$ & $\begin{array}{l}23,1 \\
\mathbf{3 5 \%} \\
\end{array}$ \\
\hline
\end{tabular}

Fuente: Elaboración propia según los datos de Eurostat, 2008-2017.

Las actividades turísticas ofrecen a las trabajadoras importantes oportunidades laborales, ya que buena parte de la imagen de marca del turismo recae en su personal, y entre sus subsectores un porcentaje importante de empleos son ocupados por éstas (Eurostat, 2018c). Del análisis de los datos de Eurostat (2018c) se detecta que existen diferencias significativas en el grado de feminización ${ }^{6}$ de las actividades turísticas españolas, siendo el transporte aéreo donde se da con menor intensidad. Por su parte en las agencias de viajes su presencia es mayoritaria, y aunque en menor grado, también en las actividades de alojamiento y servicios de comidas donde superan en todo momento el $51 \%$ de la fuerza laboral.

En efecto, el trabajo femenino suele asociarse habitualmente a contratos de tiempo parcial, y la industria turística española no es una excepción a este comportamiento. Ésta ha incrementado el uso de este tipo de contratos en el período analizado, especialmente hasta 2014, para reducirse los tres años siguientes. Esto ha hecho que la contratación a tiempo parcial suponga un $15 \%$ de las personas empleadas en este sector en el pasado 2017. Pero el reparto entre la fuerza laboral no ha sido homogéneo ya que, a pesar de haberse reducido la diferencia de incidencia de estos contratos entre ambos sexos, se ha producido más por el aumento de empleados con estas jornadas que por la disminución de las mismas en las trabajadoras turísticas (Eurostat, 2018c). De hecho, siguen siendo mayoritariamente ellas quienes presentan estas jornadas, ya que, en 2017 el $73 \%$ de los puestos de trabajo turísticos en España a tiempo parcial estaban ocupados por mujeres. Además, el número de estos contratos para las mujeres se incrementó respecto al mismo periodo del año anterior, mientras que descendían para los hombres (Eurostat, 2018c). (Tabla 3).

Tabla 3: Evolución de la incidencia del trabajo a tiempo parcial por sexo absoluta (miles de personas) y relativa en el sector turístico español.

\begin{tabular}{|c|c|c|c|c|c|c|c|c|c|c|c|}
\hline & 2008 & 2009 & 2010 & 2011 & 2012 & 2013 & 2014 & 2015 & 2016 & 2017 & $\begin{array}{c}\text { Var. } \\
08-17\end{array}$ \\
\hline Total & 2406,0 & 2396,7 & 2438,2 & 2498,1 & 2554,7 & 2707,3 & 2758,7 & 2812,2 & 2790,5 & 2818,9 & $+17 \%$ \\
\hline Mujeres & $\begin{array}{c}1909,6 \\
\mathbf{7 9} \% \\
\end{array}$ & $\begin{array}{c}1873,1 \\
\mathbf{7 8} \%\end{array}$ & $\begin{array}{c}1881,5 \\
\mathbf{7 7 \%}\end{array}$ & $\begin{array}{c}1894,2 \\
\mathbf{7 6} \%\end{array}$ & $\begin{array}{c}1921,5 \\
\mathbf{7 5} \%\end{array}$ & $\begin{array}{c}1977,4 \\
\mathbf{7 3} \%\end{array}$ & $\begin{array}{c}2021,6 \\
\mathbf{7 3 \%}\end{array}$ & $\begin{array}{c}2039,4 \\
\mathbf{7 3} \%\end{array}$ & $\begin{array}{c}2014,0 \\
\mathbf{7 2} \%\end{array}$ & $\begin{array}{c}2066,9 \\
\mathbf{7 3 \%}\end{array}$ & $+8 \%$ \\
\hline Hombres & $\begin{array}{c}496,4 \\
\mathbf{2 1} \%\end{array}$ & $\begin{array}{c}523,6 \\
\mathbf{2 2} \%\end{array}$ & $\begin{array}{c}556,6 \\
\mathbf{2 3} \%\end{array}$ & $\begin{array}{c}603,9 \\
\mathbf{2 4} \%\end{array}$ & $\begin{array}{c}633,2 \\
\mathbf{2 5 \%}\end{array}$ & $\begin{array}{c}729,9 \\
23 \%\end{array}$ & $\begin{array}{c}737,1 \\
\mathbf{2 7 \%}\end{array}$ & $\begin{array}{c}772,9 \\
\mathbf{2 7 \%}\end{array}$ & $\begin{array}{c}776,5 \\
\mathbf{2 8 \%}\end{array}$ & $\begin{array}{c}752,0 \\
\mathbf{2 7 \%}\end{array}$ & $+51 \%$ \\
\hline
\end{tabular}

Fuente: Elaboración propia según los datos de Eurostat, 2008-2017. 
El nivel retributivo percibido por las personas que trabajan en el sector turístico español es otra de las variables a analizar si deseamos conocer sus condiciones laborales y si, por tanto, la calidad del empleo asegura el buen desempeño de dichas actividades (Gobierno de España, Ministerio de Industria, Energía y Turismo y Secretaría de Estado de Turismo, 2012). En este caso, nos hemos centrado en la Hostelería, ya que es la sección donde se concentra la mayor parte de la fuerza laboral del sector turístico. La información de la Encuesta Anual de Estructura Salarial muestra para esta rama, ya en plena crisis económica, un aumento inicial de la ganancia media anual entre los años 2008 y 2010. Tras éste se inicia un descenso continuado de las mismas hasta 2014, año que registra el mínimo del período. Finaliza 2016 con un nivel salarial ligeramente superior al del momento inicial, pero lejos aún de lo registrado para 2010 (INE, 2018b).

Por otro lado, el VI Monitor Anual Adecco sobre Salarios destaca el incremento de la brecha salarial entre los distintos sectores de actividad entre los años 2012 y 2017. Por secciones de actividad la Hostelería ha registrado el menor salario medio de todas las estudiadas superando levemente los mil euros para 2017, a pesar del ligero incremento en los últimos cinco años. Esto no ha evitado que dicha remuneración haya sido prácticamente seiscientos euros inferior a la media general de todas las actividades y que se quede dos mil quinientos euros por debajo de la de Electricidad y Gas, que cuenta con los salarios más elevados de todos los analizados (Adecco, 2018:16). Cabe por tanto analizar si dentro del propio sector se pueden encontrar también diferencias significativas a la hora de percibir este salario (Tabla 4).

\section{Tabla 4: Ganancia media anual (euros) por trabajador en el subsector de la Hostelería por sexo y variación relativa de dicha ganancia por sexo (\%).}

\begin{tabular}{|c|c|c|c|c|c|c|c|c|c|c|c|}
\hline & 2008 & 2009 & 2010 & 2011 & 2012 & 2013 & 2014 & 2015 & 2016 & $\begin{array}{l}\text { Var. } \\
15-16\end{array}$ & $\begin{array}{l}\text { Var. } \\
\text { 08-16 }\end{array}$ \\
\hline Mujeres & 12405 & 12518 & 12826 & 12646 & 12694 & 12536 & 12312 & 12563 & 12609 & $+0,4$ & $+1,6$ \\
\hline Hombres & 15885 & 15940 & 16892 & 16217 & 15518 & 15553 & 15369 & 15751 & 15908 & $+1,0$ & $+0,1$ \\
\hline & \multicolumn{9}{|c|}{ Diferencia salarial absoluta por sexo $(€)$} & & \\
\hline & -3840 & -3422 & -4066 & -3571 & -2824 & -3017 & -3057 & -3188 & -3299 & & \\
\hline
\end{tabular}

Fuente: Elaboración propia según los datos de la Encuesta Anual de Estructura Salarial (INE).

Las trabajadoras que desempeñan su labor en la hostelería española han obtenido, entre 2008 y 2016 , salarios sensiblemente inferiores a los hombres empleados en la misma, superando dicha diferencia los tres mil doscientos euros para el último año disponible de la Encuesta Anual de Estructura Salarial. La tendencia global de los salarios, en el citado período, ha sido más favorable para las trabajadoras que para sus compañeros, ya que han visto incrementarse sus salarios en 1,6 puntos porcentuales. No obstante, en los dos años que cierran el análisis, 2015 y 2016, el incremento salarial es superior para ellos y la diferencia entre ambos sexos se ha incrementado de manera continua desde 2013 (INE, 2018b).

\section{Discusión y conclusiones}

En este artículo se pretendía ahondar en el análisis de la situación de la fuerza laboral turística española desde una perspectiva de género. Se ha vinculado este análisis a la evolución experimentada en la literatura especializada sobre precariedad laboral y desigualdad de género en el sector, lo que ha servido como referente básico y punto de partida. En este caso concreto, y que es lo novedoso del mismo, se ha optado por estudiar la evolución de trabajadoras en estas actividades incluyendo el modelo de tres niveles de Risman (2004) -individual, de interacción e institucional- junto con el concepto de precariedad laboral. Para ello, y centrándonos en el nivel institucional de esta autora, se han analizado en este caso dos variables referidas a la contratación a tiempo parcial y el salario percibido, las cuales son aspectos que se incluyen en el estudio de las dimensiones de la precariedad laboral (Guadarrama et al., 2012:218).

Las trabajadoras del sector turístico español sufren en mayor medida que sus compañeros unas condiciones laborales precarias, al menos en estas dimensiones analizadas a las que hemos hecho 
referencia anteriormente. A pesar de que las actividades turísticas en nuestro país han soportado la época más dura de crisis económica y destrucción de empleo siendo el auténtico motor de nuestra economía, lo cierto es que eso no ha evitado que persistan problemas estructurales en su fuerza de trabajo. Ejemplos de ello han sido el incremento de la contratación a tiempo parcial en el sector o que los salarios en la hostelería (actividad turística con mayor número de personas empleadas en España) continúe siendo una de las peor remuneradas (Adecco, 2018:16). En el primer caso, el de la contratación a tiempo parcial, aunque ellos han visto incrementado en mayor medida la incidencia de la misma no ha sido por una disminución en el caso de las mujeres, sino por un aumento de esta modalidad de contratación en el sector (Eurostat, 2018c). Ellas siguen concentrando la mayoría de estos contratos lo que tiene incidencia tanto en los salarios que perciben como, en un futuro, en sus derechos sociales referentes a la pensión de jubilación o el acceso a prestaciones por desempleo.

No obstante, no es éste el único aspecto de la precariedad laboral donde podemos observar esta desigualdad de género. De hecho, en las actividades de hostelería las trabajadoras reciben salarios inferiores a los de sus compañeros, lo que correspondería al análisis de la dimensión económica de dicho concepto. Las mujeres empleadas en las actividades turísticas obtienen remuneraciones inferiores a las de sus compañeros entre 2008 y 2016 (INE, 2018b) con independencia del año analizado. A ello debemos añadir que las actividades hosteleras cuentan con unos salarios por debajo de la media española (Adecco, 2018:16). Esta diferencia recae principalmente en el mayor peso de la temporalidad para las mujeres del sector, su mayor incidencia en contratos con jornadas inferiores a la completa y, a la segregación vertical y horizontal que les afecta (Secretaría de Acción Sindical. Confederación Sindical de Comisiones Obreras, 2015). Esto último dificulta el ascenso dentro de sus organizaciones, a pesar de que dicho sector es uno de los que mayor presencia femenina tiene entre sus trabajadores. Además, dichas trabajadoras se concentran en determinados nichos laborales asociados con frecuencia a una extensión de las labores del hogar, como tareas de limpieza de espacios, cocina, camareras de pisos, etcétera, en las que es más difícil ascender profesionalmente (Alonso, 2008:4; McKenzie, 2007:484; Obadi y Mari , 2009:102).

Además, aunque el sector turístico ha sido un nicho tradicional de empleos ocupados por mujeres, incrementando su peso en el sector en plena crisis económica, lo cierto es que también se aprecia cierto retroceso en años de recuperación (Eurostat, 2018c). Esto concuerda con las afirmaciones de que las trabajadoras del sector habrían asumido en estos años unas peores condiciones laborales -contratación a tiempo parcial y salarios inferiores-, que les habrían hecho incrementar su presencia en estas actividades, lo que se corresponden con la fuerza que tiene el nivel institucional de Risman (2004:437; Segovia-Pérez et al., 2018:189) en el que la cultura organizacional de las empresas turísticas intervienen en todo momento en la discriminación y desigualdad en este reparto de trabajo. De manera, que habrían venido a ocupar esa figura de -trabajadora adicional- en dichas actividades, confirmando así la preferencia general en el mercado laboral hacia la contratación de hombres en momentos de recuperación, como un hecho estructural (Ruesga et al., 2014:226).

Para finalizar, resultaría interesante conocer cómo evolucionan todas estas magnitudes en los próximos años e intentar descubrir si la incidencia de estas variables presenta rasgos distintivos según las distintas actividades que configuran este sector. Esto cobra especial relevancia teniendo en cuenta los previsibles efectos, de menor o mayor intensidad según las variables indicadas previamente, que la crisis sanitaria del COVID-19 tendrá para la fuerza laboral turística en general y en sus colectivos laborales en particular. En este sentido, sería necesario ampliar el análisis de las dimensiones temporal, organizacional, económica y social de la precariedad laboral (Guadarrama et al., 2012:218) en el sector turístico español desde una perspectiva de género. A su vez, convendría completar dicha investigación con una perspectiva metodológica cualitativa a través de los discursos de personas que desempeñan su trabajo en estas actividades.

\section{Bibliografía}

Adecco. 2018. VI Monitor anual Adecco sobre salarios Primera Parte. Recuperado de https://adecco.es/ wp-content/uploads/2018/04/NdP-VI-Monitor-Adecco-Salarios.-Parte-I.pdf.

Albarracín, D. y Gabinete Federal de Estudios de la Federación de Comercio, Hostelería y Turismo de CCOO. 2006. Inmigración, Relación Salarial y Hostelería. Madrid: FECOHT-CCOO (Federación de Comercio, Hostelería y Turismo de CCOO).

Alcañiz, M., Monteiro, R. 2016. She-austerity. Precariedad y desigualdad laboral de las mujeres en el sur de Europa. Convergencia. Revista de Ciencias Sociales, 23(72) septiembre-diciembre, 39-67. 
Alonso, $\mathrm{M}^{\mathrm{a}}$.M. Febrero 2008. Poder y mujer en el sector turismo: un análisis internacional de las cadenas hoteleras. En A. Téllez Infantes (Presidencia), El trabajo femenino en la empresa. Conferencia llevada a cabo en el I Congreso Internacional sobre género, trabajo y economía informal, Elche, Alicante, España. Recuperado de http://ve.umh.es/sieg.1/docs/ICongresoInternacional/.

Alonso, $\mathrm{M}^{\mathrm{a}}$.M. 2011. La dirección y el gobierno de las empresas turísticas desde la perspectiva de género. En: Alonso, María del Mar y Rodríguez, José Miguel (coords.), Turismo y género (pp.49-73). Madrid: Editorial Síntesis.

Baum, T. 2013. International perspectives on women and work in hotels, catering and tourism. Geneva: OIT.

Benach, J., Muntaner, C., Solar, O., Santana, V. y Quinlan, M. 2010. Empleo, trabajo y desigualdades en salud: una visión Global. Barcelona: Icaria Editorial.

Canalis, X. 2015, 5 agosto. El empleo turístico y de calidad retrocede, advierten profesionales y CCOO. Revista HOSTELTUR. Recuperado de http://www.hosteltur.com/112226_empleo-turistico-calidad-retrocede-advierten-profesionales-ccoo.html.

Cano, E. 1998. La lógica de la precariedad laboral: el caso de la industria valenciana del mueble. Cuadernos de relaciones laborales, 13, 207-227.

Cano, E. 2004. Formas, percepciones y consecuencias de la precariedad. Mientras Tanto, (93), 67-81.

Cañada, E. 2015. Las que limpian los hoteles. Historias ocultas de precariedad laboral. Barcelona: Icaria Editorial.

Carrasquer, P., y Torns,T. 2007. Cultura de la precariedad: conceptualización, pautas y dimensiones. Una aproximación desde la perspectiva de género. Sociedad y Utopía Revista de Ciencias Sociales, (29), 139-156. Recuperado de http://www.sociedadyutopia.es/images/revistas/29/29.pdf.

Cobo, R. 2014. Aproximaciones a la Teoría Crítica Feminista. Boletín del Programa de Formación, 1. Lima: Comité de América Latina y el Caribe para la Defensa de los Derechos de las Mujeres - CLADEM Programa de Formación. Recuperado de https://www.cladem.org/images/pdfs/publicaciones/regionales/ feminismo/aproximaciones-a-la-teoria-critica.pd.

Dumazedier, J.1968. Hacia una civilización del ocio. Madrid: Colección Estela.

Eurostat. 2018a. Eurostat your key to European statistics. About Eurostat. Recuperado de https:// ec.europa.eu/eurostat/about/overview.

Eurostat. 2018b. European Labour Force Survey. Recuperado de https://ec.europa.eu/eurostat/web/ microdata/european-union-labour-force-survey.

Eurostat. 2018c. Annual and monthly data on tourism industries. Recuperado de http://ec.europa.eu/ eurostat/data/database

Exceltur. 2017. Valoración turística empresarial tercer trimestre (verano) y expectativas para el cierre de 2017 (Perspectivas turísticas no62). Recuperado de http://www.exceltur.org/wp-content/uploads/2017/10/ Presentaci\%C3\%B3n-Informe-Perspectivas-N62-Balance-del-tercer-trimestre-2017-y-previsiones-para-cierre-de-a\%C3\%B1o.pdf

Ferguson, L. 2009. Analysing the gender dimensions of Tourism as a Development Strategy. Policy Papers del Instituto Complutense de Estudios Internacionales, PP 03/09. Recuperado de https:// ideas.repec.org/s/ucm/ppaper.html.

Figueroa, C. 2011. Las nuevas tecnologías turísticas desde la perspectiva de género. En: Alonso, María del Mar y Rodríguez, José Miguel (coords.), Turismo y género (pp. 75-98). Madrid: Editorial Síntesis.

Fuentes Guerrero, G. 2007. Sostenibilidad Turística, igual a empleo de calidad y de futuro. Estudios Turísticos, (172-173), 187-191. Recuperado de https://www.um.es/documents/378246/2964900/ Normas+APA+Sexta+Edici\%C3\%B3n.pdf/27f8511d-95b6-4096-8d3e-f8492f61c6dc.

García-Ramón, M.D., Cànoves, G., Salamaña, I., Valdovinos, N., y Villarino, M. 1995. Trabajo de la mujer, turismo rural y percepción del entorno: una comparación entre Cataluña y Galicia. Agricultura y Sociedad, (75), 115-152. Recuperado de http://www.mapama.gob.es/ministerio/pags/biblioteca/ revistas/pdf_ays/a075_03.pdf.

Ghai, D. 2003. Trabajo decente. Concepto e indicadores. Revista Internacional del Trabajo, 122(2), 125-160.

Gibson, H. 2001. Gender in tourism: Theoretical perspectives. In: Apostolopoulos, Yorghos, Sönmez, Sevil F., Timothy, Dallen J., (eds.). Women as producers and consumers of tourism in developing regions (pp. 19-43). Westport, Connecticut: Praeger.

Gobierno de España, Ministerio de Industria, Energía y Turismo y Secretaría de Estado de Turismo. 2012. Plan Nacional e integral de Turismo (PNIT) 2012-2015. Recuperado de http://www.minetad. gob.es/turismo/ca-ES/PNIT/Paginas/que-es-PNIT.aspx.

Guadarrama, R., Hualde, A., y López, S. 2012. Precariedad laboral y heterogeneidad ocupacional: una propuesta teórico-metodológica. Revista Mexicana de Sociología, 74(2), 213-243. 
Henderson, K. A. 1994. Perspectives on analyzing gender, women, and leisure. Journal of Leisure Research, 26 (2), 119-137.

Huete, R., Brotons, M., y Sigüenza, M.C. 2016. La desigualdad entre mujeres y hombres en el sector hostelero español. Estudios y perspectivas en turismo, 25(1), 3-87. Recuperado de http://www.scielo. org.ar/scielo.php?script=sci_arttext\&pid=S1851-17322016000100005\&lng=es\&tlng=es.

Instituto de Estudios Turísticos. 2010. El empleo en el sector turístico. Informe anual 2010. Recuperado de http://estadisticas.tourspain.es/es-es/estadisticas/otrasestadisticas/empleoturistico/encuestapoblacion/ paginas/informespublicaciones.aspx.

Instituto Nacional de Estadística (INE). 2008. Metodología de la Encuesta de Población Activa. Recuperado de https://www.ine.es/daco/daco43/resumetepa.pdf

Instituto Nacional de Estadística (INE). 2017. Notas de prensa Coyuntura Turística Hotelera (octubre 2017). Recuperado de http://www.ine.es/daco/daco42/prechote/cth1017.pdf.

Instituto Nacional de Estadística (INE). 2018a. Notas de prensa Encuesta Anual de Estructura Salarial (mayo 2018). Recuperado de https://www.ine.es/prensa/ees_2016.pdf.

Instituto Nacional de Estadística (INE). 2018b. Encuesta anual de estructura salarial. Recuperado de https://www.ine.es/dyngs/INEbase/es/operacion.htm?c=Estadistica_C\&cid=1254736177025\&menu $=$ resultados\&idp=1254735976596.

Iñíguez Berrozpe, T., Plumed Lasarte, M., y Latorre Martínez, M.P. 2014. Representatividad de la mujer en el sector turístico. Análisis de la desigualdad de género en entidades públicas y privadas dedicadas al turismo en España. Acciones e investigaciones Sociales, (34), 155-181. Recuperado de https://papiro.unizar.es/ojs/index.php/ais/article/view/915.

Iriondo, I. 2020. Los perfiles de riesgo de la crisis laboral del COVID-19: los jóvenes y el turismo. Unidad de cultura científica y divulgación de la Universidad Complutense de Madrid. Recuperado de https:// www.ucm.es/otri/noticias-los-perfiles-de-riesgo-de-la-crisis-laboral-del-covid-19-los-jovenes-y-el-turismo

Juárez Sánchez-Rubio, C. 2004. Sistemas de indicadores de sostenibilidad y desarrollo turístico. Aplicación a la comarca del Bajo Segura (Alicante). Investigaciones Geográficas, (33), 17-38. Recuperado de http://www.cervantesvirtual.com/portales/investigaciones_geograficas/partes/327470/n-33--2004.

Kanji, N., Menon, K. 2001 August. What does the Feminisation of Labour mean for Sustainable Livelihoods? International Institute for Environment and Development. Recuperado de http://citeseerx. ist.psu.edu/viewdoc/download?doi=10.1.1.600.486\&rep=rep1\&type=pdf.

López Bonilla, J.M., López Bonilla, L.M. 2004. Evolución y perspectivas del enfoque interdisciplinarios en el estudio del turismo. Estudios Turísticos, (160), 31-44.

Marrero Rodríguez, J.R. 2014. La sobrecualificación en el sector turístico: el caso español (1987-2011). Cuadernos de Relaciones laborales, 33(1), 149-168. http:dx.doi.org/10.5209/rev_CRLA.2015.v33.nl.48811.

Martínez-Gayo, G. 2019. ¿Empleos cinco estrellas? Reflexión sobre la precariedad laboral en la hostelería española. Revista Internacional de Turismo, Empresa y Territorio, 3(2), 1-15. https://doi.org/10.21071/ riturem.v3i2.12283.

Martínez Quintana, V. 2006. Ocio y turismo en la sociedad actual. Los viajes, el tiempo libre y el entretenimiento en el mundo globalizado. Madrid: McGrawHill.

Martínez Quintana, V. 2011. El comportamiento del consumidor turístico desde la perspectiva de género. En: Alonso, María del Mar y Rodríguez, José Miguel (coords.). Turismo y género (191-209). Madrid: Editorial Síntesis.

Martínez Quintana, V. 2019. Perspectiva sociológica turística en las sociedades del ocio. Madrid: Sanz y Torres.

McKenzie, K. 2007. Belizean women and tourism work. Opportunity or Impediment? Annals of Tourism Research, 34(2), 477-496. Recuperado de https://s3.amazonaws.com/academia.edu.documents/32990700/ Belizean_women_and_tourism_opportunity_or_impediment_Gentry_2006.pdf?AWSAccessKeyId=A KIAIWOWYYGZ2Y53UL3A\&Expires=1513083814\&Signature=YuwXym38G6Gzn1YcTcMqkTboiJ8 \%3D\&response-content-disposition=inline $\% 3 B \% 20$ filename\%3DBELIZEAN_WOMEN_AND_TOURISM_WORK_Opportun.pdf.

Menéndez Calvo, R. 2015. Balance actual de la igualdad de género en el mercado de trabajo: Crisis y reformas legislativas. Anuario de la Facultad de Derecho- Universidad de Alcalá, VIII, 225-238. Recuperado de https://dspace.uah.es/dspace/bitstream/handle/10017/24207/balance_menendez AFDUA_2015.pdf?sequence=1.

Miguélez, F. (Coord.). 2015. Diagnóstico socioeconómico sobre las políticas de empleo en España, 2012-2014. Barcelona, España: Universitat de Barona. Centre d'Estudis Sociològics sobre la Vida Qutidiana i el Treball. 
Millán Vázquez de la Torre, G., Castro Freire, M.S., y Morales Fernández, E.J. Junio 2012. Análisis del empleo femenino en el sector turístico. Un estudio de caso en la zona rural. Ponencia llevada a cabo en el IV Congreso Universitario Nacional de Investigación y Género, Sevilla, España. Recuperado de https://idus.us.es/xmlui/handle/11441/40159.

Moreno Alarcón, D. 2017. ODS Turismo y Género. Fundamentos y recomendaciones para la educación y sensibilización. Cic Bata. Córdoba: Centro de iniciativas para la Cooperación, Equality in Tourism, Consejería de Igualdad y Políticas Sociales.

Moreno Alarcón, D., Cañada, E. 2018. Dimensiones de género en el trabajo turístico. Informes en contraste 04 Turismo Responsable. Barcelona: Alba Sud Editorial.

Morini, C. 2007. The feminization of labour in cognitive capitalism. Feminist review, 87(1), 40-59.

Muñoz Benito, R. 2016. El turismo como sector estratégico en las etapas de crisis y desarrollo de la Economía Española. International Journal of Scientific Management and Tourism, 2(4), 81-115.

Muñoz-Bullón, F. 2009. The gap between male and female pay in the Spanish tourism industry.

Tourism Management, (30), 638-649.

Muñoz Seneco, D. 2012. Las mujeres y el desarrollo del turismo rural en Castilla y León (España). Geografia em Questão, 5(2), 112-127. Recuperado de http://e-revista.unioeste.br/index.php/geoemquestao/issue/view/459.

Obadić, A., y Marić, I. 2009. The significance of Tourism as an employment generator of female labour force. Ekonomska Misao I Praksa, XVIII, 93-114. Recuperado de http://www.unidu.hr/datoteke/500izb/ EKONOMSKA_MISAO_I_PRAKSA_br._1-2009.pdf

OIT Organización Internacional del Trabajo. 1999. Trabajo decente. Memoria del Director General

a la 87. ${ }^{a}$ reunión de la Conferencia Internacional del Trabajo. Recuperado de https://www.ilo.org/public/ spanish/standards/relm/ilc/ilc87/rep-i.htm.

OMT-ONU Mujeres. 2011. Global Report of Women in Tourism. Recuperado de http://www2.unwto.org/ sites/all/files/pdf/folleto_globarl_report.pdf.

OMT-ONU Mujeres. 2013. Informe mundial sobre las mujeres en el turismo 2010. Recuperado de https:// www.e-unwto.org/doi/pdf/10.18111/9789284414789.

OMT-UNWTO. 2014. Measuring Employment in the Tourism Industries: Guide with Best Practices. Recuperado de https://www.e-unwto.org/doi/pdf/10.18111/9789284416158.

OMT-UNWTO. 2017a. UNWTO World Tourism Barometer (Volume 15 October 2017). Recuperado de https://www.e-unwto.org/toc/wtobarometeresp/current.

OMT-UNWTO. 2017b. Panorama OMT del turismo internacional. Edición 2016. Recuperado de http:// www.e-unwto.org/doi/pdf/10.18111/9789284418152.

Ons-Cappa, M., Garcia-Pozo, A., Sánchez-Ollero, J.L. 2017. Incidencia de factores personales y laborales en los salario del sector hostelero: una visión de género. Cuadernos de Turismo, (39), 417-436. Doi: http://dx.doi.org/10.6018/turismo.39.290631.

Ordóñez, M. 2001. El turismo en la economía ecuatoriana: la situación laboral desde una perspectiva de género. Santiago de Chile: CEPAL.

Pieper, J. 2017. El ocio y la vida intelectual. Madrid: Rialp.

Porras, C., Hinojosa,V., Vargas, Á., De la Roja, J.M. y Canalis, X. 2015, septiembre. El empleo turístico, talón de Aquiles de España frente a los retos del futuro. Los puntos críticos de una industria basada en personas atendiendo a personas. Revista HOSTELTUR. Recuperado de http://static.hosteltur.com/ web/uploads/2015/09/empleo_turystico_tema_portada_hosteltur_septiembre_2015.pdf.

Pou, LL. 2012. Turismo y empleo una mirada realista. P3T Journal of Public Policies and Territories, 1(3), 39-44. Recuperado de http://www.raco.cat/index.php/P3T/article/view/261374/348597.

Pritchard, A. 2014. Gender and feminist perspectives in Tourism Research. En Lew A.A., Hall C.M., Williams, A.M. (Ed.), The Wiley Blackwell Companion to Tourism (314-324). Oxford, United Kingdom: Wiley-Blackwell.

Purcell, K. 1996. The Relationship between Career and Job Opportunities: Women's Employment in the Hospitality Industry as a Microcosm of Women's Employment. Women in Management

Review, 11(5), 17-24.

Ramos, V., Rey-Maquieira, J., Tugores, M. 2002. Análisis empírico de discriminación por razón de género en una economía especializada en turismo. Annals of Tourism Research, 4(1), 239-258.

Recio, A. 2007. Precariedad laboral: reversión de los derechos sociales y transformación de la clase trabajadora. Sociedad y Utopía. Revista de Ciencias Sociales, (29), 273-291.

Ribas, M.A. (s.f.). Desigualdades de género en el mercado laboral: un problema actual. Documento de trabajo de la Universitat de les Illes Balears. Recuperado de http://dea.uib.cat/digitalAssets/128/128260_4.pdf 
Rico González, M., y Gómez García, M.J. 2005. La participación empresarial de la mujer en las iniciativas de turismo rural en Castilla y León. Estudios Turísticos, (166), 97-113.

Risman, B. 1998. Gender Vertigo: American Families in Transition. Durham: Yale University.

Risman, B. 2004. Gender as a Social Structure: Theory Wrestling with Activism. Gender \& Society, 18(4):429-450. https:doi.org/10.1177/0891243204265349.

Rubio, J. 2010. Precariedad laboral en México: una propuesta de medición integral. Revista

Enfoques: Ciencia Política y Administración Pública, (13), 77-87.

Ruesga Benito, S., Martín Navarro, J.L., Pérez Ortiz, L., y Viñas Apaolaza, A. 2014. La posible recuperación económica arrastra precariedad. Análisis de coyuntura del mercado de trabajo en el primer semestre de 2014. Revista Andaluza de Trabajo y Bienestar Social, (127), 221-254. Recuperado de https://dialnet.unirioja.es/ejemplar/391024.

Sampedro, R., y Camarero, L. 2007. Mujeres empresarias en la España rural. El sujeto pendiente del desarrollo. Revista Internacional de Sociología (RIS), LXV (48), 121-146.

Santana, A. 1997. Antropología y turismo. ¿Nuevas hordas, viejas culturas? Barcelona: Ariel.

Sarasa, J. L. A. 1998. Turismo y empleo femenino. Cuadernos de Turismo, (1), 9-27.

Secretaría de Acción Sindical. Confederación Sindical de Comisiones Obreras. 2015. Informativo digital 8 de marzo día internacional de la mujer, (31). Recuperado de http://www2.ccoo.es/comunes/recursos/1/ pub147183_Informativo_Digital_Accion_Sindical_Confederal,_n_31.pdf.

Secretaría de Acción Sindical de UGT 2016. Cuatro años de reforma laboral: evolución del empleo, la contratación, los despidos, la negociación colectiva y los salarios. Recuperado de http://www.ugt.es/ Publicaciones/Cuatro_anyos_de_reforma_laboral_UGT_2016.pdf.

Segovia-Pérez, M., Figueroa-Domecq, C., Fuentes-Moraleda, L., Muñoz Bazon, A. 2018. Incorporating a gender approach in the hospitality industry: Female executives'. International Journal of Hospitality Management, (76), 184-193. Doi: https://doi.org/10.1016/j.ijhm.2018.05.008.

Sigüenza, M.C., Brotons, M., y Huete, R. 2013. The evolution of gender inequality in tourism employment in Spain. ROTUR Revista de Ocio y Turismo, (6), 188-200. Recuperado de http://hdl.handle. net/2183/12637.

Sparrowe, R.T., Iverson, K.M. 1999. Cracks in the Glass Ceiling? An empirical study of gender differences in income in the hospitality industrie. Journal of Hospitality \&Tourism Research, 23(1), 4-20.

Sue, R. 1992. El ocio. México: Ed. Fondo de Cultura Económica, $2^{\mathrm{a}}$ ed.

Swain, M. B. 1995. Gender in Tourism. Annals of Tourism Research. 22 (2), 247-266.

Swain, M. B. 2005. Las dimensiones de género en la investigación sobre turismo: temas globales, perspectivas locales. Politica y Sociedad. 42 (1), 25-37.

Torns, T., y Recio, C. 2012. Las desigualdades de género en el mercado de trabajo: entre la continuidad y la transformación. Revista de Economía Crítica, (14), 178-202. Recuperado de http://revistaeconomiacritica.org/sites/default/files/revistas/n14/Semimonografico-4.-Torns-Recio.pdf.

Torns, T. 2013. La precariedad laboral en España ¿es cosa de mujeres?. En Tejerina, Cavia, Fortino y Calderón. Crisis y Precariedad Vital. Trabajo, prácticas sociales y modos de vida en Francia y España. Valencia: Tirant lo blanch.

Torrego Serrano, F. 2002. La aportación de la mujer al turismo de negocios en Madrid. Anales de Geografía de la Universidad Complutense, Vol. Extraordinario1, 483-493. Recuperado de https:// revistas.ucm.es/index.php/AGUC/issue/view/AGUC020222/showToc.

Trujillo, J. C. 2011. Situación internacional de la perspectiva de género en las empresas turísticas. En: Alonso, María del Mar y Rodríguez, José Miguel (coords.), Turismo y género (pp.123-149). Madrid: Editorial Síntesis.

Turespaña. 2018. Estadísticas de empleo turístico. Recuperado de https://www.tourspain.es/es-es/ ConocimientoTuristico/Paginas/EmpleoTuristico.aspx.

Wlra 1994. "WLRA International Charter for Leisure Education" en European Leisure and Recreation Association (ELRA), Summer 1994, pp.13-16.

World Travel \& Tourism Council. 2014. Gender equality and youth employment: Travel \& Tourism as a key employer of women and young people. Recuperado de https://www.wttc.org/-/media/files/reports/ policy\%20research/gender_equality_and_youth_employment_final.pdf

World Travel \& Tourism Council. 2018. Viajes y Turismo. Impacto económico y asuntos globales 2018. Recuperado de https://www.wttc.org/-/media/files/reports/economic-impact-research/documents-2018/ global-economic-impact-and-issues-2018-esp.pdf?la=en. 


\section{Notas}

1 Ley 6/1994, de 16 de marzo, de ordenación del Turismo (actualmente derogada). BOPV n 70 de 14 de abril de 1994 y BOE núm. 27 de 1 de febrero de 2012. Vigente desde 15 de abril de 1994. Revisión urgente desde 01 de mayo de 2012.

2 Ley 13/2016, de 28 de julio, de Turismo. Publicado en BOPV núm. 152 de 11 de agosto de 2016 y BOE núm. 219 , de 10 de septiembre de 2016. Vigencia desde 31 de agosto de 2016.

3 La segregación en el ámbito laboral hace referencia a la desigual distribución ocupacional de hombres y mujeres en el mercado laboral. La segregación horizontal describe la situación por la que hay ocupaciones desempeñadas mayoritariamente por mujeres y otras por hombres. Por su parte la segregación vertical se vincularía con la escasa proporción de mujeres en los niveles más altos de las escalas de la jerarquía profesional (Ramos, Rey-Maquieira y Tugores, 2002:242-243).

4 La Encuesta de Población Activa define población ocupada como aquella que está formada por todas aquellas personas, de dieciséis o más años, que durante la semana de referencia han tenido un trabajo por cuenta ajena o ejercido una actividad por cuenta propia (INE, 2008).

5 Entendida ésta como la proporción de asalariados del sector turístico español con contratos temporales sobre el total de asalariados de dicho sector.

6 Entenderemos por feminización el resultado obtenido del cociente entre el total de mujeres ocupadas, en este caso en el sector turístico, entre el total de personas ocupadas en ese sector y multiplicado por 100 . 